\title{
Two Types of Spheroid Bodies in the Nigral Neurons in Parkinson's Disease
}

\author{
Tatsuo Yamada, Haruhiko Akiyama and Patrick L. McGeer
}

\begin{abstract}
Dendritic spheroid bodies (SBs) and Lewy bodies (LBs) were identified in comparable numbers in the substantia nigra pars compacta (SBC) of nine parkinsonian cases and one case of striatonigral degeneration but were not found in cases of Huntington's disease or neurologically normal controls. The immunohistochemical profile of the SBs in dystrophic dendrites of nigrostriatal dopaminergic neurons was remarkably similar to that of the LBs found within dendrites or free of the SNC neuropil. Both types of inclusions stained positively with antibodies to tyrosine hydroxylase, ubiquitin and microtubule-associated protein-2 (MAP2), and negatively for Tau-2, although they had different ultrastructural appearances. A few intracellular LBs were stained by antibodies to neurofilament proteins (NFs) 68,160 , and $200 \mathrm{kD}$, but dendritic SBs and extracellular LBs were not so stained. These data indicate that dendritic SBs and extracellular LBs may have a common molecular pathogenetic origin in Parkinson's disease. On the other hand, the SBs seen in the pars reticulata (SNR) and in the distal nigrostriatal axons even in control cases were generally stained by antibodies to NFs and ubiquitin but not to MAP2. This latter staining pattern in similar to that shown by SBs in the anterior horn in ALS and in the cerebellum of neurologically normal brains and is believed typical of axonal as opposed to dendritic SBs.
\end{abstract}

RÉSUMÉ: Deux types de corps sphéroïdes dans les neurones du locus niger dans la maladie de Parkinson. Des corps dendritiques sphéroïdes (CS) et des corps de Lewy (CL) ont été identifiés en nombres semblables dans la zona compacta du locus niger (CLN) chez neuf patients parkinsoniens et chez un cas de dégénérescence striatonigrée, mais n'ont pas été retrouvés chez des cas de maladie de Huntington ou chez des contrôles normaux. Le profil immunohistochimique des CS dans les dendrites dystrophiques des neurones nigro-striés dopaminergiques était remarquablement similaire à celui des CL retrouvés dans les dendrites ou libres dans le neuropil du CLN. Les deux types d'inclusions étaient colorés positivement par des anticorps dirigés contre la tyronsine hydroxylase, l'ubiquitine et la proteine-2 associée aux microtubules (P2AM), et négativement pour Tau-2, bien que leur ultrastructure paraissait différente. Un petit nombre de CL était coloré par les anticorps dirigés contre les protéines des neurofilaments (NFs) 68, 160 et 200 $\mathrm{kD}$, mais les CS dendritiques et les CL extracellulaires n'étaient pas colorés. Ces observations indiquent que les CS dendritiques et les CL extracellulaires ont peut-être une origine pathogénique moléculaire commune dans la maladie de Parkinson. D'autre part, les CS observés dans la żona reticulata et dans les axones nigrostriés distaux, même chez les contrôles, étaient généralement colorés par les anticorps dirigés contre les NFs et l'ubiquitine, mais pas contre la P2AM. L'aspect de cette dernière coloration est similaire à celui des CS dans la corne antérieure des cas atteints de sclérose latérale amyotrophique et dans le cervelet de cerveaux neurologiquement normaux et on le considère comme typique des CS axonaux par rapport aux CS dendritiques.

Can. J. Neurol. Sci. 1991; 18: 287-294

Spheroid bodies (SBs) are abnormal swellings of neuronal processes which appear as round, ovoid or polymorphic masses ranging in diameter from $20 \mu \mathrm{m}$ to over $120 \mu \mathrm{m} .^{1}$ They appear in a variety of pathological conditions, and even in normal aging. ${ }^{1-4}$ They develop after many types of experimental axonal injury. Their occurrence in Parkinson's disease (PD) is therefore a much less specific indicator than is the appearance of Lewy bodies (LBs). However, the presence of SBs suggest that injury, either from physical damage or some disease process, has occurred in neuronal processes.
SBs have been described as a prominent feature of Hallervorden-Spatz disease, neuroaxonal leucodystrophy, amyotrophic lateral sclerosis (ALS) and other neuroaxonal dystrophies. The SBs in ALS have been studied by immunohistochemical methods and shown to be stained by antibodies to neurofilaments (NFs) 5,6 and ubiquitin. ${ }^{7-10}$ The SBs in ALS occur in dendrites, as well as in proximal axons and perikarya, ${ }^{11,12}$ and are thought to reflect relatively early and acute changes of the neuraxis. ${ }^{4}$

From the Kinsmen Laboratory of Neurological Research, Department of Psychiatry and The Neurodegenerative Diseases Centre, University of British Columbia, Vancouver

Received August 30, 1990. Accepted in final form December 11, 1990

Reprint requests to: Dr. Tatsuo Yamada, 2255 Wesbrook Mall, University of B.C., Vancouver, British Columbia, Canada V6T IW5 
Axonal SBs, composed mainly of $10 \mathrm{~nm}$ neurofilaments, have been reported to occur in the substantia nigra pars reticulata (SNR) in various forms of PD.1,13 More recently, spindleshaped, ubiquitin positive swellings of dendrites of pigmented neurons have been reported in PD. ${ }^{14}$ However, their exact nature has not been clarified, and differentiation from extracellular LBs, which sometimes appear in elongated forms, has frequently been ambiguous in the $\mathrm{SN}$.

We describe here the different types of SBs in the $\mathrm{SN}$ and in the nigrostriatal tract in idiopathic PD and in a case of striatonigral degeneration. The immunohistochemical similarities between the dendritic SBs (which are not seen in control or Huntington disease cases) and extracellular LBs suggest that there may be a common, abnormal cytoskeletal origin.

\section{Materials ANd Methods}

The substantia nigras and nigrostriatal tracts from the brains of 9 cases of PD (age range 61-84), 1 of striatonigral degeneration (age 84), 3 of Huntington's disease (age range 49-65), and 6 of controls free of neurological disease (age range 60-76) were examined in this study. The lumbar spinal cords of 3 ALS cases and the cerebella of the neurologically normal controls were also examined for axonal SB staining.

Brains were obtained within 2-28 hours of death. The midbrain and a block which contained the nigrostriatal tract (horizontally cut at the middle and upper levels of the subthalamic nucleus) were dissected, fixed in $4 \%$ buffered paraformaldehyde for 2 days at $4^{\circ} \mathrm{C}$, and then stored at the same temperature in a solution of $15 \%$ sucrose in $0.1 \mathrm{M}$ phosphate buffered saline $(0.9 \% \mathrm{NaCl}, \mathrm{PBS}), \mathrm{pH}$ 7.4. An exception was one PD brain which was generously provided by the Canadian Brain Tissue Bank. The tissue in this case had been fixed in formalin for several months prior to being transferred to the $15 \%$ sucrose solution.

The blocks were cut on a freezing microtome at $10-30 \mu \mathrm{m}$ thickness, and rinsed for several hours with PBS containing $0.3 \%$ Triton-X100 (PBST) before incubation for 48 hours at $4^{\circ} \mathrm{C}$ with one of the following primary antibodies: anti-tyrosine hydroxylase (TH, rabbit polyclonal, Eugene Tech, 1:2,000); anti-NF protein 68,160 or $200 \mathrm{kD}$ (mouse monoclonals, Sigma, $1: 1,000)$; anti-microtubule associated protein (MAP) 1 or 2 (mouse monoclonals, Sigma, 1:1,000); Tau-2 (mouse monoclonal, Sigma, 1:1,000); or anti-ubiquitin (mouse monoclonal, generous gift of Dr. R. Kasczak, 1:10,000).

After treatment with primary antibody, the sections were washed in PBST, and treated sequentially with the appropriate Vectastain $A B C$ second antibody system according to the recommendations of the supplier (Vector). Finally, they were washed, and incubated in a staining mixture containing $0.001 \%$ 3,3'-diaminobenzidine (DAB, Sigma), $0.6 \%$ nickel ammonium sulfate (Fisher), $0.05 \%$ imidazole and $0.0003 \% \mathrm{H}_{2} \mathrm{O}_{2}$. A dark purple product formed after a few minutes, and the reaction was terminated by transferring the sections to PBST. Sections were washed, mounted on glass slides, dehydrated with graded alcohols and coverslipped with Entellan (Merck). Control sections were stained without primary antibody or with a mouse monoclonal antibody indifferent to brain tissue. All such control sections showed negative staining.
In cases where double immunostaining was carried out, excess peroxidase from the first cycle was destroyed by $0.5 \%$ $\mathrm{H}_{2} \mathrm{O}_{2}$ prior to incubation with the second primary antibody. The steps were repeated as before, except that nickel ammonium sulfate was omitted from the staining mixture so that a brown, rather than a purple, color was obtained.

Sections adjacent to or nearby those stained with primary antibodies were stained by the standard $\mathrm{H} \& \mathrm{E}$ method.

For electron microscopy, blocks of the SN of PD brains were fixed in $1 \%$ glutaraldehyde/ $4 \%$ paraformaldehyde in $0.1 \mathrm{M}$ phosphate buffer, $\mathrm{pH} 7.4$, for 24 hours at $4^{\circ} \mathrm{C}$, followed by immersion in $15 \%$ sucrose in $0.1 \mathrm{M}$ phosphate buffer, $\mathrm{pH} 7.4$, for several days at the same temperature. Sections were cut on a vibratome at $50 \mu \mathrm{m}$ thickness and incubated with antibodies to $\mathrm{TH}$ or ubiquitin for 7 days at $4^{\circ} \mathrm{C}$. The same immunohistochemical procedures used for light microscopy were followed except that the diaminobenzidine reaction was done without the presence of nickel ammonium sulfate. The sections were embedded in Epon, cut at $90 \mathrm{~nm}$ thickness, stained with uranyl acetate and lead citrate and examined with a Philips EM 201 electron microscope.

\section{Results}

\section{General Findings}

All cases of PD showed a considerable loss of neurons in the SNC, particularly in the middle and lateral divisions. There were many extraneuronal deposits of melanin, as well as fragmentation of cells and prominent reactive gliosis. SBs and LBs were identified in all cases.

The striatonigral degeneration brain showed moderate cell loss in the SNC with reactive gliosis and considerable extracellular melanin. SBs and LBs were numerous. There was moderate cell loss and glial proliferation in the posterior third of the putamen. Less prominent changes were noted in the caudate nucleus. Neurons of the globus pallidus were relatively well preserved, but gliosis was clearly evident in the external segment. Changes were observed in the locus coeruleus that were comparable to those found in the $\mathrm{SN}$. No significant changes were detected in the subthalamic nucleus, red nucleus, cerebellum or medulla oblongata.

The 3 Huntington's chorea cases all showed dramatic loss of neurons and prominent gliosis in the caudate nucleus and putamen. However, no cellular changes were noted in the SNC, and no SBs or LBs were detected in that region; a few SBs could be seen in the SNR.

The 6 control cases were each characterized by an apparently intact SNC. There was only mild cellular dropout, with little or no extracellular melanin, fragmentation of pigmented cells of LBs. No SBs were seen in the SNC although a few were found in the SNR.

\section{Lewy Bodies by Light Microscopy}

Intracellular and extracellular (intradendritic or free in the neuropil) LBs were positively stained by antibodies to $\mathrm{TH}$ (Figures 1A, D), ubiquitin (Figure 1B). Double staining for TH and ubiquitin is shown in Figure 1C, and staining for MAP2 in Figure IE. The LBs which were stained in a predominantly peripheral or laminar manner could be easily identified; there were round or ovoid in shape and $1-15 \mu \mathrm{m}$ in diameter. Other, 
diffusely stained bodies with the same general morphologies could be seen (Figures $1 \mathrm{C}$ and $2 \mathrm{C}$ ), but could not be identified as clearly LBs or SBs at the light microscopic level. The NF antibodies did not stain extracellular LBs and only stained a few of the intracellular LBs (Figure 1F).

\section{Spheroid Bodies by Light Microscopy}

a) In the SNC: In the cases of PD and in the striatonigral case, there were many more diffusely stained bodies in the SNC than in the SNR but none were found in the SNC in either Huntington disease or control brains. There were difficult to see in $\mathrm{H} \& \mathrm{E}$ stained slides but were strongly stained by antibodies to $\mathrm{TH}$ (Figures 2A, B), ubiquitin (Figure 2C) or MAP2 (Figure 2D). They were not stained, however, by antibodies to NFs, MAPl or Tau. Thus, their immunohistochemical profile was almost identical to that of extracellular LBs in the SNC (Table 1). These bodies lacked nuclei, and typically had a long diameter of about $10-25 \mu \mathrm{m}$ with a variable cross-sectional diameter.

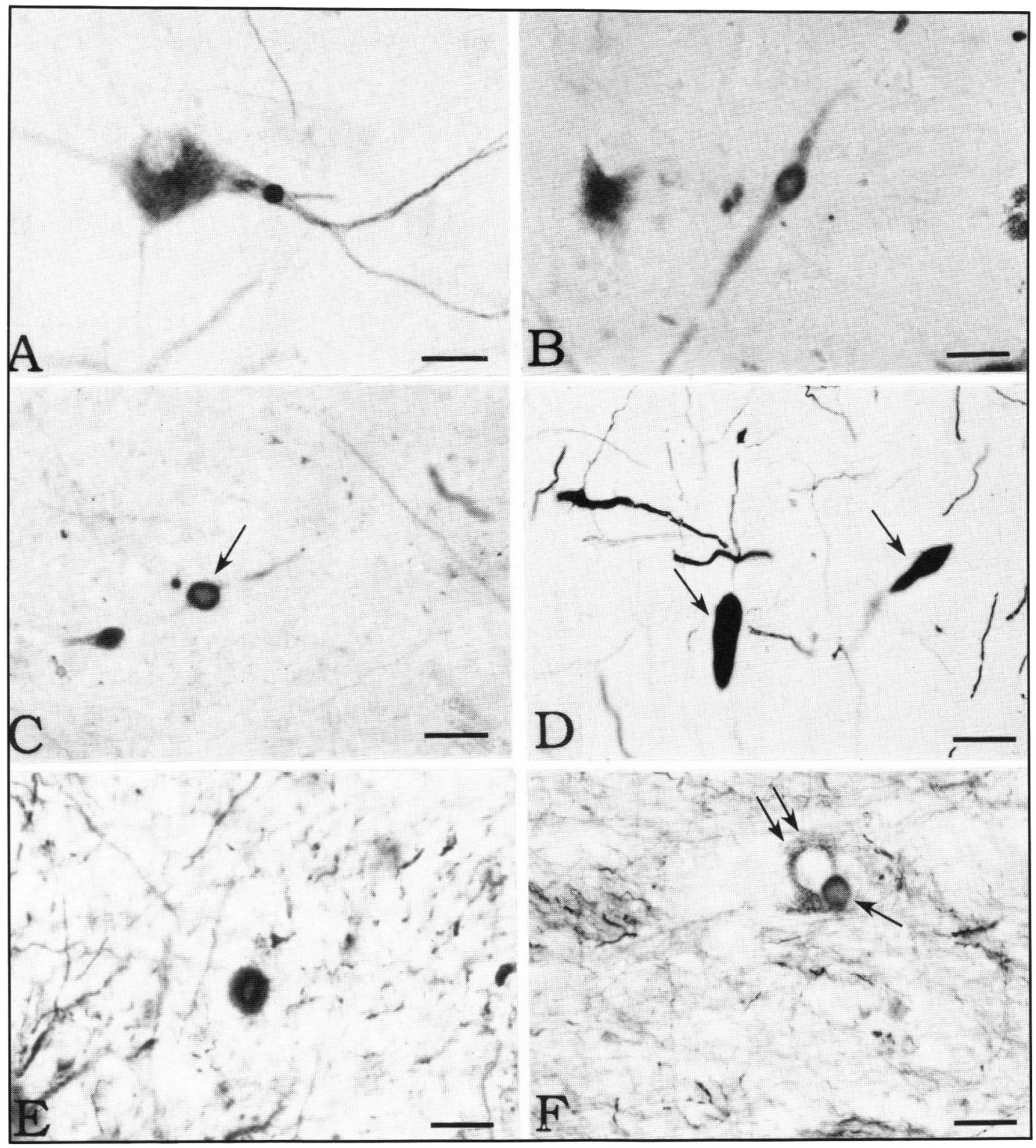

Figure I - Lewy bodies (LBS) in the SNC in parkinsonian brain. A: An intradendritic LB stained with anti-tyrosine hydroxylase (TH) antibody. B: A $L B$ within an elongated spindle-shaped $S B$ stained with anti-ubiquitin antibody. $C$ : Double immunostaining for ubiquitin and TH. In the original photomicrograph, ubiquitin was stained purple and TH brown. The double immunostained profile appeared purple brown. In the photomicrograph, it appears as a darker color compared with the more lightly stained TH positive processes. The arrowed inclusion is clearly and intradendritic $L B$ (doubly stained) but the doubly stained inclusion to the left may be either a $L B$ or $S B$. D: $T$ wo bodies stained for TH (arrows) again may be either $L B s$ (single or double) or SBs. E: A free LB in the neuropil stained by the antibody to MAP2; the intermediate zone of the $L B$ is the most intensely stained region. $F: A n$ intracellular $L B$ (arrow) stained by the antibody to neurofilament $200 \mathrm{kD}$ protein. Another $L B$ (double arrow) in the same neuron is not positively stained. Bars $=25 \mu \mathrm{m}$. 
A few were round, but most were ovoid, fusiform or clubshaped. Many of those with smaller cross-sections could clearly be seen as arising from processes of TH containing cells (Figures 2A, B). Such inclusions could not be seen in severely damaged areas of SNC, and almost all were in the vicinity of still intact neurons. In cases where the process could be followed, positive staining with antibodies to $\mathrm{TH}$ established that the neuritic swellings were located more than $500 \mu \mathrm{m}$ from the cell bodies (Figure $2 \mathrm{~A}$ ).

The pattern of staining alone does not distinguish SBs from extracellular LBs at the light microscopic level. However, on the basis of their more diffuse staining, larger size $(>20 \mu \mathrm{m}$ as opposed to $2-15 \mu \mathrm{m}$ for definitively identified extracellular LBs), and frequent spindle shapes, we considered that the bodies in Figure 2B-D were SBs. Some spindle shaped SBs, such as that in Figure 1B, may contain an LB.

b) In the SNR: Some SBs were seen in the SNR in all cases. examined. These were generally round in shape and differed from the SBs in the SNC in some of their immunochemical reactions. They were positive for some NF proteins (Figure 2E), negative for MAP2 and positive for ubiquitin. In most of these respects they resembled the SBs seen in the distal nigrostriatal

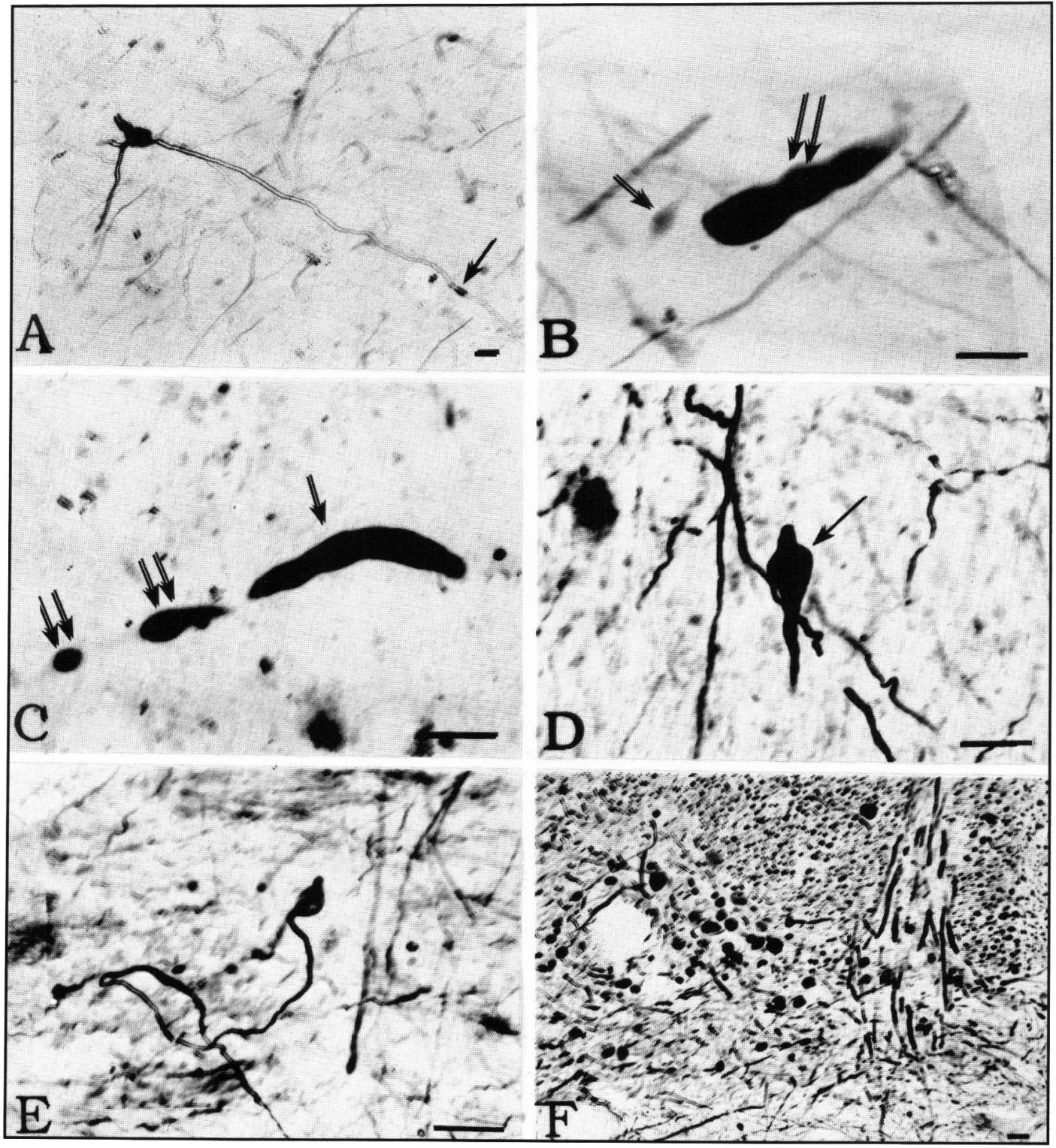

Figure 2 - Spheroid bodies (SBS) in the SNC and SNR in Parkinson's disease and striatonigral degeneration, and in the spinal cord in ALS. A, B: SBS stained by an anti-TH antibody in the SNC in Parkinson disease cases. (A) show's a small swelling of a cell process (arrow). (B) shows a large $S B$ (double arrow) and a small spindle shaped $S B$ (arrow); either may, or may not, contain an LB. C: Staining of Parkinson SNC with anti-ubiquitin antibody. A SB is indicated by the single arrow, but it is unclear whether the structure marked with double arrows are formed by $L B s$, SBs or SBs containing LBS. D: A SB in the SNC of a case of striatonigral degeneration stained for MAP2 (arrow); again this $S B$ might contain a LB.E: A SB in the SNR of a parkinsonian case stained for neurofilament $160 \mathrm{kD} . F$ : $S B$ s in the anterior horn in ALS lumbar cord stained for neurofilament $160 \mathrm{kD}$. Bars $=25 \mu \mathrm{m}$. 
Table 1: Immunohistochemical Profiles of Lewy Bodies and Spheroid Bodies*

\begin{tabular}{|c|c|c|c|c|}
\hline $\begin{array}{r}\text { Su } \\
\text { Staining for I }\end{array}$ & $\begin{array}{l}\text { Lewstantia i } \\
\text { Lewy } \\
\text { Intracell. }\end{array}$ & $\begin{array}{l}\text { Nigra Pars } \\
\text { Bodies } \\
\text { Extracell }\end{array}$ & $\begin{array}{l}\text { Compacta } \\
\text { Spheroid } \\
\text { bodies }\end{array}$ & $\begin{array}{c}\text { Nigrostriatal Tract** } \\
\begin{array}{c}\text { Spheroid } \\
\text { bodies }\end{array}\end{array}$ \\
\hline $\begin{array}{l}\text { Ubiquitin } \\
\text { Tyrosine }\end{array}$ & +++ & +++ & +++ & + \\
\hline hydroxylase & $e+++$ & +++ & +++ & +++ \\
\hline MAP 2 & ++ & ++ & ++ & 0 \\
\hline NF 200 & + & 0 & 0 & ++ \\
\hline NF 160 & + & 0 & 0 & ++ \\
\hline NF 60 & + & 0 & 0 & 0 \\
\hline MAP1 & 0 & 0 & 0 & 0 \\
\hline Tau & 0 & 0 & 0 & 0 \\
\hline
\end{tabular}

* Frequency of staining is indicated by 0 , none; + , a few; ++ , moderate; +++ , many.

** The spheroid bodies in the substantia nigra pars reticulata showed a similar immunohistochemical profile to those in the nigrostriatal tract except that they were negative for tyrosine hydroxylase.

*** The spheroid bodies in the substantia nigra pars compacts were defined by size, shape and diffuse staining as indicated in the text. tract (Table 1), in the lumbar cord in ALS cases (Figure 2G) and in the cerebellum in neurologically normal controls, although the staining with antibodies to NFs and ubiquitin tended to be much stronger in the spinal and cerebellar inclusions. The staining for $\mathrm{TH}$ seen in the SBs in the nigrostriatal tract was not, however, seen in the SBs in the SNR, lumbar cord or cerebellum

c) In the Distal Nigrostriatal Tract: Numerous SBs were seen in the tract in the Huntington cases, and in both PD cases and controls over the age of 70 years. The numbers were similar in all of these cases. Few, if any, however, were seen in the younger PD and control cases. These axonal SBs could be seen on staining with antibodies to TH (Figure 3B), NFI60 kD (not shown), or NF200 kD (Figure 3D). They were small (less than 2 $\mu \mathrm{m}$ in diameter) and round. Double staining for $\mathrm{TH}$ and ubiquitin (Figure 3C) showed that some were also positive for the latter (Table 1) although such staining tended to be less intense than seen in SBs in the SNC.

\section{Ultrastructures of LBs and SBs in the SNC in PD}

An intracellular LB positively stained in its periphery for TH was found to have fibers of about $20 \mathrm{~nm}$ diameter radiating in

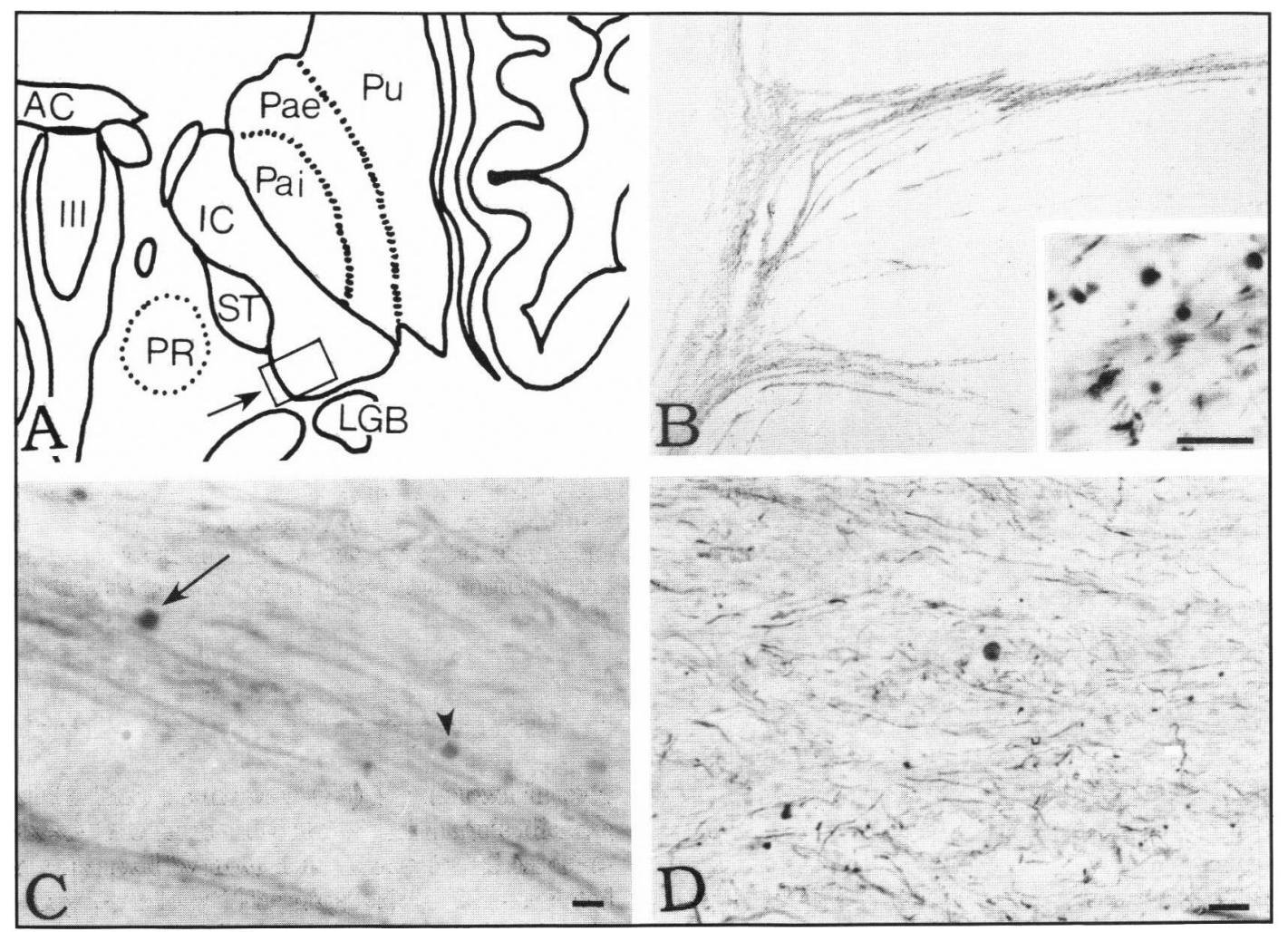

Figure 3 - Axonal SBs in the distal nigrostriatal tract in cases of Parkinson's disease. A: Schema of the plane of section (horizontal cut at the middle level of the subthalamic nucleus). The boxed area (arrow') is that shown in Figure B. III, 3rd ventricle; AC, anterior commissure; IC, internal capsule; LGB, lateral geniculate body; Pai. globus pallidus, internal segment: Pae, globus pallidus, external segment; Pu, putamen: PR, prerubral radiations: ST, subthalamic nucleus. B: Many small round SBs can be seen in the nigrostriatal tract projecting medially to or through the internal capsule in this section stained for TH. The inset show's the SBs in the TH-positive tract at a higher magnification. $C$ : Section doubly stained for ubiquitin and TH. In the original section, wbiquitin was stained purple and TH brown. A doubly immunostained $S B$ (arrow), which in the original section was purple-brown, appears as a darker profile than the single TH stained SBs (arrowhead) and the TH positive axons. D: $S B$ s positively stained by the anti-NF100 $\mathrm{kD}$ antibody. Bars $=25 \mu \mathrm{m}$. 
various directions (Figures $4 \mathrm{~A}$ and $4 \mathrm{~B}$ ). An extracellular LB of ovoid shape stained for ubiquitin showed deposits of reaction product in the periphery (Figure $4 \mathrm{C}$ ) and many irregular, broken fibers with a diameter of about $15 \mathrm{~nm}$ (Figure 4D).

In electron micrographs stained for $\mathrm{TH}$, the ovoid, round (Figures $4 \mathrm{E}$ and $4 \mathrm{~F}$ ) or fusiform SBs of the SNC could be seen to be composed of coarse fibrillary material uniformly spread throughout the structures. The diameter of the fibers was $20-25 \mathrm{~nm}$.

\section{DisCuSSION}

We believe that these data indicate that there are at least two different types of positive SBs which we are calling "dendritic" and "axonal" SBs. Dendritic SBs are seen in the SNC in parkinsonism and striatonigral degeneration but are not seen there in Huntington's disease or controls. They are therefore probably specific for diseases involving degeneration of the

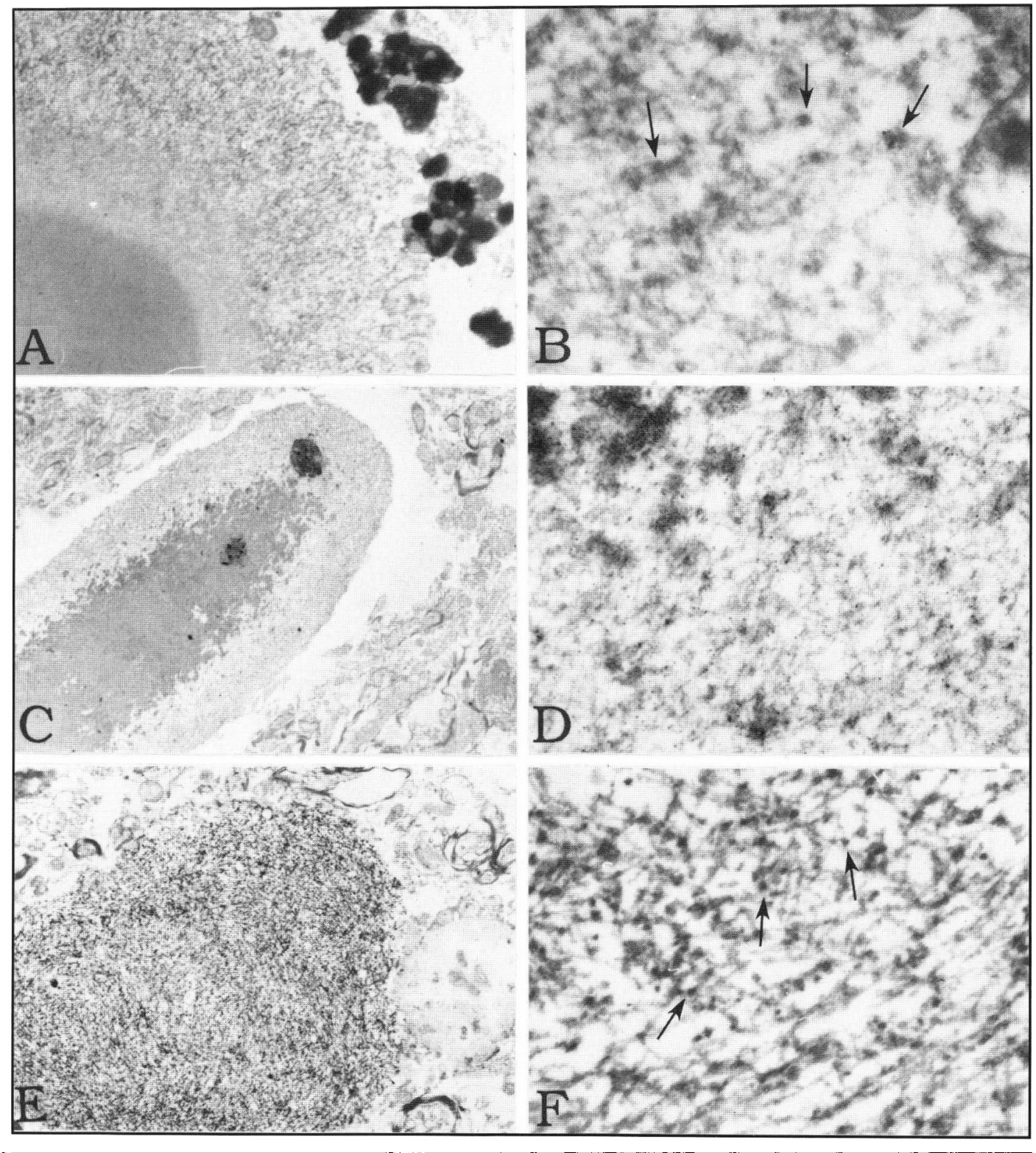

Figure 4 - Electron microscopic photomicrographs of intra- and extra-cellular $L B$ s and dendritic SBs in the SNC. $A-D$ : Intracellular LBs stained by an anti-TH antibody $(A \times 4640 ; B \times 28928)$ are compared with extracellular $L B$ s stained for ubiquitin ( $C \times 1984 ; D \times 28928)$. The peripheral fiber structures of the latter show less oriented radiations and far more broken structures. At low magnification $(A$ and $C$ ), immunodeposits were concentrated in the peripheral zone. In $D$, the immunodeposits appear as many fine dots. $E, F$ : Dendritic SBs stained for $T H(E x$ 4640; $F \times 28928$ ). The round $S B$ with a process shown in $E$ is composed of fibers about $20 \mathrm{~nm}$ in width. Staining was by the uranyl acetate-lead citrate method. Arrows in B and F indicate immunodeposits. 
nigrostriatal dopaminergic tract. Dendritic SBs are more common in the SNC in these diseases than are LBs but are difficult to see with standard histopathological stains such as $\mathrm{H} \& \mathrm{E}$. They are, however, easily detected by immunohistochemical staining with antibodies to ubiquitin, TH or MAP2. In such stained sections these SBs can often be identified as part of dendritic processes. The ultrastructural features are consistent with such an origin. LBs outside the perikaryon show many similarities to swellings of neuronal processes. There were many bodies seen in this study which would not be identified as pure dendritic SBs since differentiation from LBs was only definitive at the electron microscopic level. Although the filamentous ultrastructure of SBs does differ from the ultrastructure of extracellular LBs, the apparently identical immunohistochemical staining pattern (Table 1) suggests there may be a common molecular pathogenetic origin. The strong labeling with antibodies to ubiquitin, a highly conserved protein known to facilitate ATP-dependent proteolysis, 16 is consistent with the hypothesis that both LBs and dendritic SBs contain cytoskeletal proteins designated for proteolysis; they differ, however, from such ubiquitin-positive inclusions as Pick bodies or the neurofibrillary tangles of Alzheimer disease in that they do not stain for Tau.

Axonal SBs, on the other hand, are seen in the SNR and in the distal nigrostriatal tract in cases of Huntington's disease and aged controls, as well as in PD and striatonigral degeneration. It appears, therefore, that these are not pathognomonic of degenerative diseases of the nigrostriatal dopamine system. They differ from dendritic SBs in that they are less ubiquitin positive, MAP2 negative, but NF positive with the antibodies used in this study. Axonal SBs have been previously reported in normal aging, $1-4$ in various axonal dystrophies, ${ }^{1}$ and in diseases, such as $\mathrm{ALS}^{4,5.7-12}$ or other motor neuron disease, ${ }^{5}$ where there is specific neuronal degeneration. Small swellings $(<25 \mu \mathrm{m})$ in the neuropil of ALS spinal cord have been termed globules, ${ }^{4}$ but they are reported to have a similar immunohistochemical profile and probably are a type of axonal SBs. The extent of staining for ubiquitin of axonal SBs seems to vary considerably, even in the same region of a given brain, suggesting that the damage indicated by the appearance of a SB is not always sufficient to demand rapid proteolysis.

A special word needs to be said about staining for neurofilament proteins. Two of the three particular antibodies to neurofilaments used in this work clearly stained axonal SBs in the nigrostriatal tract and the SNR; all three stained some but not all of the intracellular LBs, but none of the three stained extracellular LBs or the dendritic SBs in the SNC. These same NF antibodies, in our hands, strongly stained normal neuronal processes and the SBs in the spinal cord of ALS cases and the cerebellum of controls. In contrast to our results, the literature generally indicates that most LBs stain positively for epitopes of NFs. ${ }^{17-24}$ This staining, however, has generally been seen with antibodies which recognize phosphorylated forms of the NFs, and the degree of phosphorylation seems to be critical to antibody recognition. It may well be that NFs are incorporated into LBs in significant concentrations but are altered in structure sufficiently so that they are not detected by the antibodies that we used. An alteration of NF diameter from 7.5 to $20 \mathrm{~nm}$ in LBs has been reported. ${ }^{25}$ Alternatively, it is possible that, once they become extracellular, LBs partially degrade and lose their immunoreactivity to some anti-NF antibodies.
It seems clear that various types of abnormal structures may be found in pathological tissue, that only some of these types may be pathognomonic, and that identification and classification of these structures may be made possible by the immunohistochemical application of a variety of antibodies to various normal and abnormal structural proteins.

\section{ACKNOWLEDGEMENT}

This research was supported by grants from the Medical Research Council of Canada, the American Health Assistance Foundation and the Alzheimer Society of B.C., as well as donations from individual British Columbians. We thank Dr. R. Kasczak for his generous gift of the antibody to ubiquitin and Ms Joane Sunohara for technical assistance.

\section{REFERENCES}

1. Jellinger K. Neuroaxonal dystrophy: its natural history and related disorders. Prog Neuropathol 1973; 2: 129-180.

2. Smith MC. Argyrophilic bodies in the human spinal cord. J Neurol Neurosurg Psychiatry 1955; 18: 13-16.

3. Clark AW, Parhad IM, Griffin JW, et al. Neurofilamentous axonal swellings as a normal finding in the spinal anterior horn of man and other primates. J Neuropathol Exp Neurol 1984; 43: 253262.

4. Carpenter $S$. Proximal axonal enlargement in motor neuron disease. Neurology 1968; 18: 842-851.

5. Schmidt MI, Carden MJ, Lee VM-Y, et al. Phosphate dependent and independent neurofilament epitopes in the axonal swellings of patients with motor neuron disease and controls. Lab Invest 1987; 56: 282-294.

6. Manetto, V, Sternberger NH, Perry G, et al. Phosphorylation of neurofilaments is altered in amyotrophic lateral sclerosis. J Neuropathol Exp Neurol 1988; 47: 642-653.

7. Leigh PN, Anderton $\mathrm{BH}$, Dodson $\mathrm{A}$, et al. Ubiquitin deposits in anterior horn cells in motor neuron disease. Neurosci Lett 1988; 93: 197-203.

8. Kato T, Katagiri T, Hirano A, et al. Lewy body-like hyaline inclusions in sporadic motor neuron disease are ubiquitinated. Acta Neuropathol (Berl) 1989; 77: 391-396.

9. Lowe J, Aldridge F, Lennox G, et al. Inclusion bodies in motor cortex and brainstem of patients with motor neurone disease are detected by immunocytochemical localization of ubiquitin. Neurosci Lett 1989; 105: 7-13.

10. Migheli A, Autilio-Ganbetti P, Gambetti C, et al. Ubiquitinated filamentous inclusions in spinal cord of patients with motor neuron disease. Neurosci Lett 1990; 114: 5-10.

11. Hirano A, Inoue K. Early pathological changes of amyotrophic lateral sclerosis: electron microscopic study of chromatolysis, spheroids and Bunina bodies. Neurol Med (Tokyo) 1980; 13: 148-160.

12. Sasaki S, Kamei H, Yamane K, et al. Swelling of neuronal processes in motor neuron disease. Neurology 1988; 38: 1114-1118.

13. Jellinger K. Pathology of Parkinson's syndrome. In: Calne DB (ed.). Handbook of Experimental Pharmacology, Drugs for the Treatment of Parkinson's Disease. Springer-Verlag, 1989; 88: 47-94.

14. Leigh PN, Probst A, Dale GE, et al. New aspects of pathology of neurodegenerative disorders as revealed by ubiquitin antibodies. Acta Neuropathol (Berl) 1989; 79: 61-72.

15. Forno LS. Pathology of Parkinson's disease: the importance of the substantia nigra and Lewy bodies. In: Stern GM (ed.) Parkinson's Disease. Baltimore: The John Hopkins University Press, 1990: 185-238.

16. Hershko A, Ciechanover A. The ubiquitin pathway for the degradation of intracellular proteins. In: Cohn WE, Moldave K (eds.). Progress in Nucleic Acid Research and Molecular Biology. New York: Academic Press Inc., 1986; 33: 19-56.

17. Goldman, JE, Yen S-H, Chiu F-C, et al. Lewy bodies of Parkinson's disease contain neurofilament antigens. Science 1983; $221: 1082-1084$. 
18. Nakazato X, Sasaki A, Hirato J, et al. Immunohistochemical localization of neurofilament protein in neuronal degenerations. Acta Neuropathol (Berl) 1984; 64: 30-36.

19. Kahn J, Anderton BH, Gibb WRG, et al. Neuronal filaments in Alzheimer's, Pick's and Parkinson's diseases. N Engl J Med 1985: 313: 520-521.

20. Forno LS. The Lewy body in Parkinson's disease. Adv Neurol 1986; 45: 35-43.

21. Forno LS, Sternberger LA, Sternberger NH, et al. Reaction of Lewy bodies with antibodies to phosphorylated and non-phosphorylated neurofilaments. Neurosci Lett 1986; 64: 253-258.

22. Papola MA. Lewy Bodies of Parkinson's disease. Immune electron microscopic demonstration of neurofilament antigens in constitutent filaments. Arch Pathol Lab Med 1986; 110: 1160-1163.
23. Galloway PG, Grundke-Iqbal I, Iqbal K, et al. Lewy bodies contain epitopes both shared and distinct from Alzheimer neurofibrillary tangles. J Neuropath Exp Neurol 1988; 47: 654-663.

24. Bancher $\mathrm{C}$, Lassmann $\mathrm{H}$, Budka $\mathrm{H}$, et al. An antigen profile of Lewy bodies: Immunocytochemical indication for protein phosphorylation and ubiquitination. J Neuropath Exp Neurol 1989; 48: 81-93.

25. Duffy PE, Tennyson VM. Phase and electron microscopic observations of Lewy bodies and melanin granules in the substantia nigra and locus coeruleus in Parkinson's disease. J Neuropath Exp Neurol 1965; 24: 398-414. 